\title{
EDITORIAL ASPECTOS ÉTICOS DE LAS PUBLICACIONES MÉDICAS
}

Cómo citar: Morla E. Editorial. cysa [Internet]. 17 de junio de 2020 [citado 17 de junio de 2020];4(2):3-4. Disponible en: https:// revistas.intec.edu.do/index.php/cisa/article/view/1769

La publicación es el último eslabón de una investigación. Es a través de ella que comunicamos a la comunidad científica nuestros hallazgos, para que sean de utilidad en la salud de la población. Hay todo un universo de revistas donde publicar; desde las llamadas de alto impacto hasta las más modestas, locales o regionales.

Corresponde al editor y a los revisores vigilar la identidad de la publicación, y que en la misma se respetaron los derechos de las personas objeto de estudio, presentando el investigador constancia de que su trabajo fue evaluado por un comité de ética. Se aplicará, además, un programa de fraude o similares para garantizar el correcto uso del contenido empleado en la presentación.
La Asociación Mundial de Editores Médicos (WAME) trata de establecer una cooperación internacional entre los editores para facilitar la comunicación entre ellos, mejorar las publicaciones y que estas cumplan con los más altos estándares de calidad vigilando los principios éticos y científicos en las mismas.

Otras entidades, como el Directorio de Revistas de Acceso Abierto (DOAJ) y la Asociación de Publicaciones Académicas de Acceso Abierto (OASPA) abogan por un acceso global abierto general para todas las revistas, cuidando siempre los aspectos éticos en las publicaciones.

\section{Dr. Elbi Morla}

Editor

ORCID: 0000-0001-6406-5709

Correo-e: elbi.morla@intec.edu.do 